\title{
Total Knee Arthroplasty in Patients with Dialysis: Early Complications and Mortality
}

\author{
Jen-Hung Chen, Feng-Chih Kuo, Jun-Wen Wang
}

Background: Total hip arthroplasty (THA) in patients on long-term hemodialysis may result in a high prevalence of complications which related to nature of the disease, and associated cardiovascular conditions. However, the result of total knee artrhopalsty (TKA) in those patients is not clear. The purpose of this study was to retrospectively evaluate the early mortality and complications of TKA performed in patients with dialysis.

Methods: We retrospectively evaluated 15 dialysis patients (18 knees) who underwent TKA using antibiotic-loaded cement fixation. Fourteen patients had maintained hemodialysis and one patient had continuous ambulatory peritoneal dialysis. The function of the knee was evaluated before operation and postoperatively using Knee Society evaluating system. Postoperative complications and mortality were recorded for all patients. The average follow up period was 25 months (6 to 59 months).

Results: $\quad$ There were no mortalities including short-term ( $\leq 90$ days) or long-term ( $>90$ days) follow up. The mean knee and function scores improved from preoperative 36 points (27 46) and 19.4 points (10 35) to 79 points (68 87)

\section{At a Glance Commentary \\ Scientific background of the subject}

Patients on long-term hemodialysis may result in a high prevalence of complications after operation. The complication after TKA in dialysis patients has been rarely reported. The aim of this study was to retrospectively evaluate the early mortality and complications of TKA performed in dialysis patients.

\section{What this study adds to the field}

According to our study, TKA with antibiotic-loaded cement resulted in a substantial low short-term mortality and deep infections in patients with dialysis. However, patients need to be informed of the possible risk of postoperative cardiovascular or cerebrovascular thromboembolism before the operation, due to nature of the ESRD. and 81 points (70 95) respectively at the latest follow up. One $(6.7 \%)$ patient had early postoperative pneumonia ( $\leq 90$ days). The late ( $>90$ days) complication rate was $20 \%$ including 1 sepsis with toe gangrene, 1 recurrent stroke and 1 acute myocardiac infarction. There was no deep prosthetic joint infection or loosening of the components.

Conclusion: TKA with antibiotic-loaded cement resulted in a substantial low short-term mortality and deep infections in 15 patients with dialysis. However, a longer term follow up is necessary.

(Biomed J 2014;37:84-89)

Key words: dialysis, end-stage renal disease, total knee arthroplasty

$\mathrm{T}^{\mathrm{s}}$ otal knee arthroplasty (TKA) has been a standard procedure for patients with late-stage osteoarthritis of the knee. The survival rate of the implant is $>90 \%$ at 20 years and the infection rate is less than $1 \%$ within the general population. ${ }^{[1-3]}$ How about the results of TKA in patients treated by dialysis because of end stage renal disease
(ESRD)? There has been some reports indicating a high mortality and morbidity in dialysis patients undergoing total hip arthroplasty (THA). ${ }^{[4-6]}$ Sakallale et al., reported a 58\% mortality rate, $58 \%$ early complication rate and a $13 \%$ deep infection rate after 15 THAs done in 12 dialysis patients. ${ }^{[5]}$ These complications may be related to the inherent nature

From the Department of Orthopaedic Surgery, Kaohsiung Chang Gung Memorial Hospital, Chang Gung University, College of Medicine, Kaohsiung, Taiwan

Received: Dec. 12, 2012; Accepted: Apr. 17, 2013

Correspondence to: Dr. Jun-Wen Wang, Department of Orthopedic Surgery, Kaohsiung Chang Gung Memorial Hospital. 123, Dapi Rd., Niaosong, Kaohsiung 833, Taiwan (R.O.C.). Tel: 886-7-7317123 ext. 8003; Fax: 886-7-7354309; E-mail: wangjw@ adm.cgmh.org.tw

DOI: $10.4103 / 2319-4170.117897$ 
of the disease, metabolic imbalance, or perioperative conditions. The complications after TKA in dialysis patients were rarely reported. Recently, McCleery et al. ${ }^{[7]}$ in their large cohort study of rate of infection and revision in TKA patients with renal disease showed that dialysis patients had significant risks of late infection $(8.03 \%, p<0.001)$ and early revision $(3.7 \%, p<0.001)$. Both renal failure and renal dialysis were independent risk factors for early infection and revision respectively. However, the other complications and mortality rate were not mentioned. The purpose of our study was to retrospectively review the ESRD patients with dialysis who had a TKA and determine the rate of 90-day complications and mortality of those patients after the TKA procedure.

\section{METHODS}

Between 2007 and 2012, a total of 18 knee arthroplasties were performed in 15 patients ( 3 men and 12 women) with dialysis-dependent renal failure. The indications for TKA of these patients were severe osteoarthritis of the knee with failure of conservative treatment. Fourteen patients were maintained on hemodialysis, with treatments provided on a thrice-weekly schedule. One patient was maintained on continuous ambulatory peritoneal dialysis (CAPD). The duration of dialysis before operation was 6.16 years (1 to 17). The mean age of the patients at the time of total knee arthroplasty (TKA) was 64.2 years (48 to 73). This retrospective study was approved by Institutional Review Board of Chang Gung Memorial Hospital.

The dialysis patient population carries a higher risk of comorbid conditions including coronary artery disease (CAD),${ }^{[8,9]}$ impaired myocardial function, ${ }^{[10]}$ and carotid plague $^{[11]}$ that related to postoperative complications. Carotid artery stenosis are potential causes of perioperative or postoperative stroke. ${ }^{[12,13]}$ Therefore, routine consultation of cardiologists and neurologists were conducted for those patients at clinic if they were willing to have a TKA. The cardiovascular survey included 12-lead electrocardiogram (ECG), echocardiography and thallium-201 myocardial perfusion scintigraphy according to guidelines on perioperative cardiovascular evaluation and care for noncardiac surgery, reported by American Heart Association (AHA). ${ }^{[14]}$ The neurologic survey included duplex ultrasounds of the carotid artery to evaluate the extent of stenosis of carotid artery. The exclusion criteria were patients with cardiovascular conditions requiring further evaluations and treatment according to the guidelines of AHA and American College of Cardiology, ${ }^{[14]}$ or patients with carotid stenosis with higher risks for stroke. ${ }^{[13]}$ Patients who met the exclusion criteria were explained the higher risk of postoperative complications and mortality and need to be followed at a cardiovascular or neurologic clinic. In the study period, there were nine patients who met the exclusion criteria and did not have knee replacement because of higher surgical risks. The 15 patients in this study who did not meet the exclusion criteria were explained about the possible postoperative complications, and were still eligible for TKA with cautions. None of these 15 patients were initially excluded, and were later included for TKA.

Preoperative comorbidities were also recorded, including diabetes mellitus (DM) in 3 patients, hypertension in 11 patients, CAD in 2 patients, stroke history in one patients and upper gastrointestinal (UGI) bleeding history in 5 patients. The previous preoperative infection history was also noted, including two having urinary tract infection history and one having liver abscess history. Three patients were also noted with malignancy history, which included ureter cancer, heptaocellular carcinoma, and renal cell carcinoma. Of them, two patients suffered from renal failure. Other significant medical history included hypothyroidism and liver cirrhosis [Table 1]. The pre-operative American Society of Anesthesiologists Classification (ASA) of each patients, haemoglobin ( $\mathrm{Hb})$ level, prothrombin time (PT), activated partial thromboplastin time (APTT) were recorded as well. Each patient received dialysis within 24 hours before operation

\section{Surgical technique}

All patients received primary TKA using the same prosthesis (Nex-Gen, Legacy Posterior Stabilized Prosthesis; Zimmer, Warsaw, IN, USA). Prophylactic parenteral antibiotics with cefazolin were given routinely for one day after operation. The antibiotic- loaded bone cement was used during operation for preventing post-operative infection. Vancomycin ( $1 \mathrm{~g}$ in $40 \mathrm{~g}$ of bone cement) was used in 5 knees and tobramycin-loaded cement $(1 \mathrm{~g}$ in $40 \mathrm{~g}$ of bone cement) (Stryker Orthopaedics, Mahwah, NJ), after it was commercially available in Taiwan, was used in 13 knees. Postoperatively, all patients were scheduled for continuing dialysis starting on postoperative day 1 and every other day thereafter as usual until discharge.

\section{Postoperative follow up}

All patients returned to the clinic 2 weeks after surgery for suture removal and clinical examination. The clinical and radiographic evaluation of all patients was performed before operation and at 6 weeks, 12 weeks, 6 months and then annually during follow up using the clinical and radiographic evaluation system of American Knee Society. ${ }^{[15]}$ All complications including medical complications, wound infection, necrosis, deep infections, prosthetic instability or loosening and mortality within 90 days or one year postoperatively were recorded. 
Table 1: Patients' data and complications as seen in the study

\begin{tabular}{|c|c|c|c|c|c|c|c|c|c|}
\hline \multirow{2}{*}{$\begin{array}{l}\text { Patient } \\
\text { Number }\end{array}$} & \multirow{2}{*}{$\begin{array}{l}\text { Age at } \\
\text { operation } \\
\text { (years) }\end{array}$} & \multirow{2}{*}{ Comorbidities } & \multicolumn{2}{|c|}{ Preoperative } & \multirow{2}{*}{$\begin{array}{l}\text { Dialysis } \\
\text { duration } \\
\text { before op } \\
\text { (years) }\end{array}$} & \multirow{2}{*}{$\begin{array}{l}\text { Antibiotics } \\
\text { in cement }\end{array}$} & \multicolumn{2}{|c|}{ Postoperative } & \multirow[t]{2}{*}{ Complications } \\
\hline & & & $\begin{array}{l}\text { Knee score } \\
\text { (points) }\end{array}$ & $\begin{array}{l}\text { Function score } \\
\text { (points) }\end{array}$ & & & $\begin{array}{l}\text { Knee score } \\
\text { (points) }\end{array}$ & $\begin{array}{l}\text { Function } \\
\text { score } \\
\text { (points) }\end{array}$ & \\
\hline 1 & 72 & $\begin{array}{l}\text { DM, HTN, UTI, } \\
\text { CAD PU }\end{array}$ & 41 & 35 & HD 1 & Vancomycin & 87 & 90 & $\begin{array}{l}\text { CAD s/p stent at } \\
16 \text { months }\end{array}$ \\
\hline \multirow[t]{2}{*}{2} & 54 & Hypothyroidism & 30 & 10 & HD 11 & Vancomycin & 82 & 80 & Nil \\
\hline & 55 & Hypothyroidism & 30 & 10 & HD 12 & Vancomycin & 82 & 80 & Nil \\
\hline \multirow[t]{2}{*}{3} & 61 & PU, UTI & 34 & 25 & HD 7 & Vancomycin & 77 & 90 & Nil \\
\hline & 62 & PU & 31 & 25 & HD 8 & Vancomycin & 78 & 90 & Nil \\
\hline 4 & 66 & HTN & 33 & 20 & HD 7 & Tobramycin & 82 & 80 & Nil \\
\hline 5 & 48 & DM, HTN & 27 & 15 & HD 1 & Tobramycin & 82 & 75 & Nil \\
\hline 6 & 69 & HTN & 36 & 20 & HD 17 & Tobramycin & 76 & 75 & Nil \\
\hline \multirow[t]{2}{*}{7} & 65 & HTN & 43 & 25 & PD 1 & Tobramycin & 82 & 90 & Nil \\
\hline & 67 & HTN & 42 & 25 & PD 3 & Tobramycin & 82 & 90 & Nil \\
\hline 8 & 62 & Ureter cancer & 38 & 30 & HD 7 & Tobramycin & 87 & 95 & Nil \\
\hline 9 & 70 & $\begin{array}{l}\text { Polycystic kidney } \\
\text { disease, HTN }\end{array}$ & 30 & 20 & HD 1 & Tobramycin & 76 & 80 & Nil \\
\hline 10 & 71 & $\begin{array}{l}\text { DM, HTN, CAD } \\
\text { with stent, PU, } \\
\text { liver abscess } \\
\text { history }\end{array}$ & 36 & 15 & HD 3 & Tobramycin & 68 & 70 & $\begin{array}{l}\text { Pneumonia } \\
\text { related sepsis } \\
\text { at } 10 \text { months } \\
\text { Left } 5^{\text {th }} \text { toe } \\
\text { amputation due } \\
\text { to gangrene at } \\
12 \text { months }\end{array}$ \\
\hline 11 & 68 & HTN, CVA, PU & 46 & 10 & HD 10 & Tobramycin & 72 & 70 & $\begin{array}{l}\text { Pneumonia } \\
\text { at } 1 \text { month } \\
\text { Pneumonia } \\
\text { related sepsis } \\
\text { at } 4 \text { months } \\
\text { Recurrent stroke } \\
\text { at } 10 \text { months }\end{array}$ \\
\hline 12 & 62 & $\begin{array}{l}\text { HTN, liver } \\
\text { cirrhosis, HCC }\end{array}$ & 27 & 10 & HD 8 & Tobramycin & 77 & 70 & Nil \\
\hline 13 & 62 & HTN & 38 & 25 & HD 10 & Tobramycin & 82 & 80 & Nil \\
\hline 14 & 69 & $\mathrm{RCC}$ & 41 & 15 & HD 3 & Tobramycin & 77 & 80 & Nil \\
\hline 15 & 73 & HTN, asthama, PU & 43 & 15 & HD 1 & Tobramycin & 77 & 80 & Nil \\
\hline
\end{tabular}

Abbreviations: DM: Diabetes mellitus; CAD: Coronary artery disease; CVA: Cerebrovascular accident; UTI: Urinary tract infection; RCC: Renal cell carcinoma; HCC: Hepatocellular carcinoma; PU: Peptic ulcer; HD: Hemodialysis; PD: Peritoneal dialysis; op: operation; s/p: status post

\section{Statistical analysis}

The preoperative and postoperative knee score and function score were compared statistically using Wilcoxon Singed Rank test with statistical significance set at $p<0.05$. The statistical comparisons were made using Statistical Package for Social Science (SPSS) software (Version 15; Chicago, IL, USA).

\section{RESULTS}

The preoperative ASA classification of all patients was 2 in two patients and 3 in thirteen patients, average $\mathrm{Hb}$ values was $11.4 \mathrm{~g} / \mathrm{dl}$ (range, 9.5-13.4) average PT was 10.46 seconds (range, 9.3-18) and APTT was 30.72 seconds (range,
23.9 60.2).The average hospital stay in these patients was 6.72 days (range, 6 9). And all patients completed at least post-operative 90-day follow up. The average follow up time was 25 months (range: 6 59).

The preoperative Knee Society knee score was 36 points (range, 27 46) and it improved to 79 points (range, $68 \sim 87)$ at the latest follow up $(p<0.001)$. The patient with low score (68 points) was a case with toe gangrene who underwent toe amputation at follow up period. The Knee Society function score improved from preoperative 19.4 points (range, 10 35) to 81 points (range, 70 95) at the latest follow up $(p<0.001)$ [Table 1].

Among the 18 knee arthroplasties, one patient had an early complication (within 90 days and diagnosed as 
pneumonia), due to which she was admitted in the chest ward for further treatment. The 90-day complication rate was $6.7 \%$. There were 3 patients $(20 \%)$ who presented late complications ( $>90$ days) after operation. The one with early complication of pneumonia, suffered from pneumonia related sepsis and was readmitted 4 months after operation. The patient was also diagnosed with recurrent stroke later. Another patient was hospitalized for pneumonia related sepsis 10 months after left TKA. He also received left $5^{\text {th }}$ toe amputation surgery due to gangrene, which was on the same side of knee arthroplasty. A third patient had cardiac catheterization and stenting due to heart attack 16 months after operation [Table 1].

No wound necrosis or prosthetic joint infection was noted in patients, and was not seen even in those who developed sepsis as a complication during the follow up. No mortality was noted during the follow up period of the patients. There were no prosthetic failure noted, or loosening requiring a revision surgery was also not seen during the radiographic and clinical evaluations during follow up.

\section{DISCUSSION}

The reports on perioperative mortality associated with TKA were sporadic. In series ranging from 2736 to 253,370 arthroplasties, the mortality rate has ranged from $0.1 \%$ to $0.8 \%{ }^{[16-18]}$ However, the duration of postoperative period in which the mortality was calculated, varied from 30 days to one year. We chose 90 -day mortality rate after TKA (death occurring intraoperatively, during hospitalization and within 90 days after surgery) according to Gill et al. ${ }^{[19]}$ who reported $0.46 \%$ 90-day mortality rate after primary TKA in general population. They also concluded that increasing patient age and associated comorbidities were the risk factors for mortality. The ESRD substantially increases the risks of death, cardiovascular disease, and use of specialized health care. ${ }^{[20]}$ The dialysis patients are facing an annual mortality rate of approximately $25 \%$ due to disease nature and being associated with a high prevalence of cardiovascular disease. ${ }^{[9]}$ Therefore, we considered that 90 days may be the optimal duration for perioperative mortality for this particular patients group after TKA. Sakallale et al. ${ }^{[5]}$ reported 7 mortalities (58\%) of 12 dialysis patients after THA. Of them, 4 patients (33\%) died within one year. Liberman et al., reported 5 deaths (45\%) of dialysis patients after THA at an average follow up of 55 months. ${ }^{[21]}$ Four were secondary to sepsis and the other related to renal failure. In our series, there were no 90-day or one-year mortalities in our 15 patients after TKA at a mean follow up of 25 months. But we did have two patients complicated with sepsis and pneumonia postoperatively. However, they survived after meticulous medical care. Patients with long-term dialysis are associated with renal anemia, hypoproteinemia and decreased immunity which increase the rate of postoperative infection. ${ }^{[4,22,23]}$ However, with improvement of surgical technique and medical care in the past decade, the mortality rate of dialysis patients after joint replacement will be lower than previously reported. $\mathrm{Li}$ et al., reported one death of 21 patients with hemodialysis 7 years after THA. ${ }^{[24]}$

The second important issue of TKA in dialysis patients is deep infection. According to McCleery et al., patients with renal failure had a significantly increased risk of early and late infection after TKA. ${ }^{[7]}$ The rate of deep infection of the prosthetic joint after THA in dialysis patients ranged from $0 \%$ to $19 \%{ }^{[4-6,21,25]}$ Some patients died because of deep infection of the hip. ${ }^{[4]}$ Therefore, aside from systemic antibiotic therapy, aseptic surgical technique and improvement of the surgical environment such as ultraviolet light, we have started to use antibiotic-loaded cement with vancomycin or commercial tobramycin-loaded cement (Stryker Orthopedics, Mahwah, New Jersey) in dialysis patients undergoing TKA since 2007. Previous studies have shown that combined use of gentamycin-load bone cement and systemic antibiotic therapy is an efficient strategy to reduce the risk of infection after primary hip arthroplasty. ${ }^{[26]}$ In the early study period, we added vancomycin $1 \mathrm{~g}$ in $40 \mathrm{~g}$ bone cement as antibiotic-loaded bone cement for infection prophylaxis. Since 2010, tobramycin-loaded cement (Simplex P bone cement with $1.0 \mathrm{~g}$ of tobramycin per $40 \mathrm{~g}$ of bone cement) was available in our hospital and then it was used in patients with higher risk for infection after joint arthroplasty. The factors associated with higher risk of infection after total joint arthroplasty include patients with revision surgery, a history of infection or a decreased immunity. ${ }^{[27]}$ ESRD is one of the disease entities that decrease the immunity of the patients. ${ }^{[23]}$ Efficacy of tobramycin-loaded cement used during total joint arthroplasty for the reduction of deep sepsis is well-demonstrated previously in vitro, ${ }^{[28,29]}$ in vivo ${ }^{[30,31]}$ and clinical studies. ${ }^{[32,33]}$ The elution properties of vancomycin may not be as effective as that of tobramycin in clinical study, ${ }^{[29]}$ however, our results showed that there were no deep prosthetic joint infections of the dialysis patients using tobramycin or vancomycin-loaded in the bone cement. We considered that the results of low mortality and low infection in dialysis patients is attributed to routine use of antibiotics-loaded cement during TKA and postoperative meticulous medical care.

The safety of antibiotic-loaded cement in patients with impaired renal function has been concerned. Previous studies have demonstrated the systemic safety of high-dose vancomycin and gentamycin antibiotics spacer. ${ }^{[34]}$ Walenkamp and Vree have suggested that local gentamycin treatment may be used in renal impairment. ${ }^{[35]}$ However, recently van Raaij et al., reported a case of acute renal failure following use of gentamycin-loaded cement beads and block spacer for infected TKA. ${ }^{[36]}$ Curtis et al., reported acute renal failure 
in a patient with renal insufficiency undergoing treatment of infected TKA with combined use of tobramycin-cefazolin bone cement and block spacer. ${ }^{[37]}$ Both reports had used a high dose of aminoglycoside ( $2 \mathrm{~g}$ of gentamycin-loaded block spacer and 7 chains of $0.945 \mathrm{~g}$ gentamycin bone cement beads in van Raaij report, ${ }^{[36]} 3.6 \mathrm{~g}$ tobramycin and $3 \mathrm{~g}$ cefazolin loaded bone cement and block spacer in Curtis report ${ }^{[37]}$ ) and Palacos cement. Investigators compared the elution power of tobramycin from different cements and found significant more elution from Palacos than Simplex cement. ${ }^{[38]}$ Penner et al., demonstrated in vitro that combining antibiotics including tobramycin in the bone cement may alter the porosity of bone cement and allow more elution of tobramycin. ${ }^{[39]}$ In our series, the choice of aminoglycoside in the bone cement was tobramycin manufactured by Stryker Orthopedics (Simplex-P bone cement, $1 \mathrm{~g}$ tobramycin per $40 \mathrm{~g}$ bone cement), the dose of tobramycin is much lower than that used in infected TKA and we did not add other antibiotics in the bone cement. The safety of commercial tobramycin-loaded cement has been well investigated. ${ }^{[40]}$ Nevertheless, the use of high dose antibiotics-loaded cement in patients with renal insufficiency should be cautious.

Our 90-day complication rate was $6.7 \%$. This was a 68-year-old woman developed pneumonia and sepsis one month after TKA. Fortunately, with use of tobramycin-loaded cement during TKA, there has been no prosthetic joint infection since then. Stenvinkel et al. ${ }^{[11]}$ reported that higher association of atherosclerotic cardiovascular disease and carotid plagues in patients with chronic renal failure compared with healthy controls. Our results of three late complications including recurrent stroke in 1, toe amputation due to peripheral artery occlusion disease in 1 , and acute myocardial infarction in 1 which were all related to atherosclerotic vascular disease, the preexisting comorbidity of all 3 patients.

We acknowledged the limitations of the study. First, our patients group is small. It is because the life expectancy of the dialysis patients is not long enough for development of severe arthritis of the knee and the dialysis patients may be reluctant to accept TKA. However, this study is the first report of mortality and complications of dialysis patients undergoing TKA. Second, the follow up period was short (25 months). However, this study focused on short-term complications and mortality only because the late complications and mortality are mostly caused by nature of the disease or associated cardiovascular disease of the dialysis patients.

In conclusion, TKA with antibiotic-loaded cement is an effective treatment modality for dialysis patients with severe knee arthritis. Our results showed a substantial low short-term mortality and deep infections in 15 selected dialysis patients undergoing TKA. However, patients need to be informed of the possible risk of postoperative cardiovascular or cerebrovascular thromboembolism before the operation, due to nature of the ESRD.

\section{REFERENCES}

1. Cloutier JM. Results of total knee arthropasty with a non-constrained prosthesis. J Bone Joint Surg Am 1983;65:906-19.

2. Gill GS, Joshi AB, Mills DM. Total condylar knee arthroplasty. 16- to 21-year results. Clin Orthop Relat Res 1999;367:210-5.

3. Peersman G, Laskin R, Davis J, Peterson M. Infection in total knee replacement, a retrospective review of 6489 total knee replacement. Clin Orthop Relat Res 2001;392:15-23.

4. Naito M, Ogata K, Shiota E, Nakamoto M, Goya T. Hip arthroplasty in haemodialysis patients. J Bone Joint Surg Br 1994;76:428-31.

5. Sakulkale DP, Hozack WJ, Rothman RH. Total hip arthroplasty in patients on long-term renal dialysis. J Arthrolasty 1999;14:571-5.

6. Toomey HE, Toomey SD. Hip arthropasty in chronic dialysis patients. J Arthroplasty 1998;13:647-52.

7. McCleery MA, Leach WJ, Norwood T. Rates of infection and revision in patients with renal disease undergoing total knee replacement in Scotland. J Bone Joint Surg Br 2010;92:1535-9.

8. Bennett WM, Kloster F, Rosch J, Barry J, Porter GA. Natural history of asymptomatic coronary arteriographic lesions in diabetic patients with end-stage renal disease. Am J Med 1978;65:779-84.

9. Sarnak MJ, Levey AS. Cardiovascular disease and chronic renal disease: A new paradigm. Am J Kidney Dis 2000;35:S117-31.

10. Foley RN, Partrey PS, Sarnak MJ. The clinical epidermiology of cardiovascular disease in chronic renal disease. Am J Kidney Dis 1998;32:S112-9.

11. Stenvinkel P, Heimbürger O, Paultre F, Diczfalusy U, Wang T, Berglund L, et al. Strong association between malnutrition, inflammation, and atherosclerosis in chronic renal failure. Kidney International 1999;55:1899-911.

12. Blacker DJ, Flemming KD, Wizdicks EF. Risk of ischemicc stroke in patients with symptomatic vertebrobasilar stenosis undergoing surgical procedures. Stroke 2003;34:2659-63.

13. Blacker DJ, Fleming KD, Link MJ, Brown RD Jr. The preoperative cerebrovascular consultation: Common cerebrovascular questions before general or cardiac surgery. Mayo clin Proc 2004;79:223-9.

14. Fleisher LA, Beckman JA, Brown KA, Calkins H, Chaikof EL, Fleischmann KE, et al. 2009 ACCF/AHA focused update on perioperative beta blockade incorporated into the ACC/AHA 2007 guidelines on perioperative cardiovascular evaluation and care for noncardiac surgery. J Am Coll Cardiol 2009;54:e13-118.

15. Ewald FC. The Knee Society total knee arthroplasty roentgenographic evaluation and scoring system. Clin Orthop Relat Res 1989;248:9-12.

16. Lavernia CJ, Guzman JF. Relationship of surgical volume to short-term mortality, morbidity and hospital charges in arthroplasty. J Arthroplasty 1995;10:133-40.

17. Parvizi J, Sullivan TA, Trousdale RT, Lewallen DG. Thirty-day mortality after total knee arthroplasty. J Bone Joint Surg Am 2001;83:1157-61.

18. Taylor HD, Dennis DA, Crane HS. Relationship between mortality rates and hospital patient volume for Mecicare patients undergoing 
orthopaedic surgery of the hip, knee, spine and femur. J Arthroplasty 1997; 12:235-42.

19. Gill GS, Mills D, Joshi AB. Mortality following primary total knee arthroplasty. J Bone Joint Surg Am 2003;85:432-5.

20. Go AS, Chertow GM, Fan D, McCulloch CE, Hsu CY. Chronic kidney disease and risks of death, cardiovascular events, and hospitalization. New Engl J Med 2004;351:1296-305.

21. Lieberman JR, Fuchs MD, Haas SB, Garvin KL, Goldstock L, Gupta R, et al. Hip arthroplasty in patients with chronic renal failure. J Arhtroplasty 1995;10:191-5.

22. Bradley JR, Evans DB, Calne RY. Long-term survival in haemodialysis patients. Lancet 1987;1:295-6.

23. Raska K Jr, Raskova J, Shea SM, Frankel RM, Wood RH, Lifter J, et al. $\mathrm{T}$ cell subsets and cellular immunity in end-stage renal disease. Am J Med 1983;75:734-40.

24. Li WC, Shih CH, Ueng SW, Shih HN, Lee MS, Hiesh PH. Uncemented total hip arthroplasty in chronic hemodialysis patients. 20 hips reviewed after 2-13 years. Acta Orthop 2010;81:178-82.

25. Sunday JM, Guille JT, Torg JS. Complications of joint arthroplasty in patients with end-stage renal disease on hemodialysis. Clin Orthop Relat Res 2002;397:350-5.

26. Espehaug B, Engesaeter LB, Vollset SE, Havelin LI, Langeland N. Antibiotic prophylaxis in total hip arthroplasty. Review of 10,905 primary cemented total hip replacements reported to the Nerwegian arthroplasty register, 1987 to 1995 . J Bone Joint Surg Br 1997;79:590-5.

27. Jiranek WA, Hanssen AD, Greenwald AS. Antibiotic-loaded cement for infection prophylaxis in total joint replacement. J Bone Joint Surg Am 2006;88:2487-500.

28. Nelson CL, Griffin FM, Harrison BH, Cooper RE. In vitro elution characteristics of commercially and noncommercially prepared antibiotic PMMA beads. Clin Orthop Relat Res 1992;284:303-9.

29. Von Frauhofer JA, Polk HC, Seligson D. Leaching of tobramycin from PMMA bone cement beads. J Biomed Mater Res 1985;19:751-6.

30. Adams K, Couch L, Cierny G, Calhoun J, Mader JT. In vitro and in vivo evaluation of antibiotic diffusion from antibiotic-impregnated polymethylmethacrylate beads. Clin Orthop Relat Res 1992;278:244-52.

31. Brien WW, Salvati EA, Klein R, Brause B, Stern S. Antibiotic impregnated bone cement in total hip arthroplasty: An in vivo comparison of the elution properties of tobramycin and vancomycin. Clin Orthop Relat Res 1993;296:242-8.

32. Pritchett JW, Bortel DT. Tobramycin-impregnated cement in total hip replacements. Orthop Rev 1992;21:577-9.

33. Soto-Hall R, Saenz L, Tavernetti R, Cabaud HE, Cochran TP. Tobramycin in bone cement: An in depth analysis of wound, serum and urine concentrations in patients undergoing total hip revision arthroplasty. Clin Orthop Relat Res 1983;175:60-4.

34. Springer BD, Lee GC, Osmon D, Haidukewych GJ, Hanssen AD, Jacofsky DJ. Systemic safety of high-dose antibiotic-loaded cement spacers after resection of an infected total knee arthroplasty. Clin Orthop Relat Res 2004;427:47-51.

35. Walenkamp GH, Vree TB. Treatment of a patient with impaired renal function with gentamicin-PMMA-beads. Arch Orthop Trauma Surg 1981;99:137-41.

36. Curtis JM, Sternhagen V, Batts D. Acute renal failure after placement of tobramycin-impregnated bone cement in an infected total knee arthroplasty. Pharmacotherapy 2005;25:876-80.

37. van Raaij TM, Visser LE, Vulto AG, Verhaar JA. Acute renal failure after local gentamicin treatment in an infected total knee arthroplasty. J Arthroplasty 2002;17:948-50.

38. Greene N, Holtom PD, Warren CA, Ressler RL, Shepherd L, $\mathrm{McPherson} \mathrm{EJ}$, et al. In vitro elution of tobramycin and vancomycin polymethylmethacrylate beads and spacers from Simplex and Palacos. Am J Orthop 1998;27:201-5.

39. Penner MJ, Masri BA, Duncan CP. Elution characteristics of vancomycin and tobramycin corbined in acrylic bone-cement. J Arthroplasty 1996;11:939-44.

40. Sterling GJ, Crawford S, Potter JH, Koerbin G, Crawford R. The pharmacokinetics of Simplex-tobramycin bone cement. J Bone Joint Surg Br 2003;85:646-9. 